\title{
An Investigation Study of Academic Writing Problems Faced by Arab Postgraduate Students at Universiti Teknologi Malaysia (UTM)
}

\author{
Mustafa N Abdulkareem \\ Department of Curriculum and Instruction, Universiti Teknologi Malaysia, Johor, Malaysia
}

\begin{abstract}
This study aimed to investigate the academic writing problems encountered by Arab speaking postgraduate students at Universiti Technologi Malaysia (UTM). There are two research questions of this study. The first question involved the identification of mistakes that Arab speaking postgraduate students commit in academic writing at UTM. The second question dealt with the problems Arab speaking students' perceived in academic writing. The data for the study were collected through distributing a set of questionnaires and writing task. The respondents of this study were 85 Arab speaking postgraduate students who come from different Arabic countries like Iraq, Yemen, Sudan, Saudi Arabia, Algeria, Libya, Palestine, and Syria who enrolled for the academic session of 2011/2012. A snowballing technique was used to determine the samples of this study. A set of the questionnaires were distributed to 80 of the respondents to reveal their opinions towards the causes of academic writing problems. Another 5 students were given a writing task which was to write two short paragraphs regarding their fields of works. The students' writing was sent to an expert of English language to identify the mistakes made by the students. The findings of the study nevertheless could be used to recommend effective teaching approaches to teach academic writing that are currently used by English language teachers and specialists.
\end{abstract}

Index Terms - Arab students, academic writing, committed mistakes, writing task, questionnaires

\section{INTRODUCTION}

Academic writing plays an essential role in learning a foreign language. Non- native speakers of the English language should be familiar with writing processes, elements, and features like formality, objectivity, and complexity in order to use the language precisely and accurately. Abdulwahed, S (2010) pointed out that English writing affords students the opportunity to think critically and provides the motivation to learn certain aspects of academic writing like using effective word expressions and strong vocabulary. Moreover, academic writing involves certain features like critical thinking and self- expression that students should receive during the courses they attend like IEC or IELTS. These courses allow students to practice the four language skills (listening, speaking, reading, and writing) through activities such as tutorials, daily quizzes, and final examinations. There are other aspects of academic writing which must be studied and mastered such as organizing paragraphs by using a strong style of word structures, paraphrasing, and appropriate conjunctions. There also certain aspects involve the use of certain steps which must be followed by students such as understanding and summarizing the passage before writing, eliminating and breaking up long sentences or changing them, and using synonyms to express the same meaning. Furthermore, (Zamel, 1983) stated that learners may find out effective ideas during the process of writing in order to get an accurate use of language during academic writing activities. Thus, academic writing requires student to be familiar with the types of academic writing like descriptive, narrative, and illustrative, approaches (process, genre, and product), and strategies (giving feedback, using critical thinking, and paraphrase the sentences in their own writing).

The challenges of academic writing among students can be related to the discipline of writing like management, understanding, and communication discipline. The students in many cases misunderstand and have difficulties towards the way of academic writing instruction been given by nonnative speakers of English language. In addition, the guidelines of academic writing instructions are not so clear for their level to be implemented. In other words, (Fawwaz \& Ahmed, 2007) identified some problems related to students' thinking in managing some tests to improve their academic texts such as the use of cohesion aspects, weak connection among the words, and the lack in producing certain types of disciplines in academic writing.

\section{Objectives of Study}

1- To investigate the type of mistakes that Arab students commit in academic writing at UTM.

2- To investigate the problems that Arab students face in academic writing academic writing at UTM.

Significance of Study

This study focuses on the challenges and the mistakes encountered by Arab postgraduate students in order to identify the suggestions and solutions for the recommended future researches. This study is a crucial issue to be dealt with as it reveals the problems that Arab students face when writing especially the lack of methods and the ways of teaching 
English academic writing. The present study also describes and focuses on certain procedures related to emphasize on some approaches and strategies to increase students' writing skills and perceptions by enhancing their writing proficiency to meet their needs and follow some writing discipline for future work.

\section{Problems faced by Arab Students}

The study examines academic writing procedures to reveal the problems that Arab speaking postgraduate students face. Also, the study deals with the mistakes that Arab speaking postgraduate students make in writing short paragraphs regarding their fields of work.

Arab students face many problems when paraphrasing. For example, students are incapable of using their own words or reformat sentences based on their own critical thinking, and reorganize sentences to be more effective academically. Other problems encountered by Arab students are interfering of their native language (Arabic language). The difference occurs between Arab students and native speakers of English language, who have diverse writing styles, abilities, and backgrounds. Arab students are incapable of organizing the functions of writing, the process of reading to writing, and then the interfering of Arabic language (L1) with the second language (L2) that prevents the use of critical thinking and the process of paraphrasing in making new word structure based on their own perspectives without changing the meaning of the words. Most students commit many mistakes related to sentence structure. For Instance, grammatical mistakes are in syntactical as well as in organizing new word expressions as most of the instructions given in Arabic and because the teacher is a non-native speaker. Rabab'ah (2001) stated that the lack of communication among Arab students in dealing with all four language skills is due to inappropriate resources and the weaknesses in context that are given to these students.

\section{REVIEW OF LITERATURE}

\section{Characterization of Academic Writing}

Academic writing can be characterized as the construction and development of techniques taught in universities such as organizing and generating students' ideas and critical thinking, and developing vocabulary and grammatical syntax. Additionally, students in English writing classes should receive more exposure to those features which offer strong vocabulary, good sentence structures, and the organization of paragraphs based on punctuation marks and conjunctions. (Montgomery \& Baker, 2007) pointed out that teachers should identify and emphasize the process of academic writing for students. Thus, teachers need to establish and encourage students' attitudes towards the basic elements of academic writing such as definition, strategies, and difficulties. In addition, in order to increase students' perceptions about academic writing, they have to modify their assumptions about their needs, improvement, and proficiency level to become better writers.

Other perspectives like ( $\mathrm{Li}, 2007)$ stated that writers' constructions have to address some beliefs about the identifications and development of English as a second language (ESL) contexts regarding the use of effective lesson plans in teaching academic writing. Thus, students can interact with beliefs, culture, and identity of academic writing to modify and set their needs

\section{Perceptions of Students towards Academic Writing}

In a second language acquisition (SLA), students need to understand the procedure of academic writing such as developing new strategies, using adequate approaches, and finding out the best solutions for their problems. Most researchers have concentrated on teaching academic writing effectively among Arab students to develop the selfesteem and critical thinking in teaching writing skills, features of academic writing, and composition tasks.

Daoud \& Al-Hazmi (2002) claimed that non-native speakers of the English language can explore a new world of academic writing by measuring self-integration of learning and by getting the opportunity to think critically in order to express themselves, thereby making an intellectual commitment to get and generate something meaningful through writing. Non-native speakers can develop their accuracy towards academic writing by engaging in various programs within teaching and learning environments. Students can achieve their academic purposes by developing certain aspects of cultural features such as communicative interaction, appreciation of cultural background, and engaging in meaningful and interactive tasks. This will be achieved by making students deal with the objectives of the English language curriculum and language skills being used in classroom activities

\section{Strategies of Academic Writing}

The importance of using strategies in academic writing can support the specialists of second language acquisition (SLA) for the development and enhancement of learners' proficiency level. Ellis, R (1985) stated that language learning strategy (LLS) is one of the three processes to develop second language knowledge.

In many studies, there is an emphasis on effective strategies that are used to improve students' performance such as critical thinking, paraphrasing, and mind mapping. Moreover, these strategies can be considered as the measurement of students' writing abilities that can be analyzed and modified during the process of teaching academic writing.

\section{A. Using Corrective Feedback}

Most English writers deal with certain steps and stages to enhance the process of English academic writing and to improve and develop its strategies and features. For example, from the grammatical aspect, there are certain steps and procedures students should take into consideration such as the use of correct tenses. 
Kepner (1991) suggested that student mistakes can be corrected and analyzed to increase their writing accuracy by defining two important things. The first involves the process of acquiring forms and structures of second language acquisition (SLA). The other involves the ability and willingness of teachers to deal with practical problems in terms of corrective feedback. Lundstrom \& Baker (2009) mentioned teachers can conduct constructive feedback to contribute to improve students' performance in academic writing. Besides, students will be introduced and classified as givers and receivers to reveal their considerations and perceptions towards the progress of their writing courses to achieve their goals in learning if the trainee writers share the same cultural and educational background.

Many studies like Ferris \& Hedgcock (2005) claimed that many English language writing teachers used one-on-one strategy in corrective feedback to provide and generate the opportunity for clarification and notification to reveal students' mistakes. Moreover, a number of studies are concerned with implementing these kinds of techniques among ESL students in order to reduce their mistakes and examine their future needs

\section{B. Using Mind Mapping and Critical Thinking}

There are many facts that students become capable of doing through the acquisition of academic writing. For instance, students need to be critical, need to be sort of kinesthetic, and be capable of synthesis. In addition, they need to have a good introduction to instruct their paragraphs and ideas should be well organized. Thus, they have to be more accurate in analyzing and developing their critical thinking in order to summarize and conclude their writing professionally.

Scane, Guy, \& Wenstrom (1991) mentioned that brainstorming can motivate a students' writing by increasing their creativity in certain tasks related to English as a foreign language (EFL) environment. Furthermore, students can express their thoughts and good writing under the process of brainstorming stages, assisting students to generate new ideas and develop their skills for the tasks of academic writing. Harmer (2001) mentioned that brainstorming techniques can make students create their own ideas and thinking to improve their knowledge before writing, and it can then be used at any level and under any situation.

Buzan, (1993) described the concepts of brainstorming that students need to acquire in order to use its powerful tools to overcome their problems in organizing their thoughts and skills.

\section{Methodology}

Respondents: The respondents of the study were Arab speaking students come from different countries and they are perusing their postgraduate degrees in various fields of study. Also, they studied for their first degrees in their own countries. The respondents are from Iraq, Sudan, Syria, Yemen, Libya, Palestine, and Algeria. They were asked to respond to the writing task and a set of questionnaires at the university.

Instrumentation: A set questions of questionnaires were used for this paper and a simple writing task. The questionnaires were distributed to 80 students, and another 5 were given a writing task. The 80 respondents were required to give their perceptions by responding to 17 questions. The other 5 students were required to give their feedbacks and responses by writing two short of paragraphs. The first part of the questionnaires asked for demographical information of the students which included country and English proficiency. The second part contained 17 question items asking about the perceptions of respondents towards the causes of academic writing problems; namely vocabulary, sentence structure, organizing paragraphs, and getting feedbacks. The second instrument which was a simple writing task was distributed to another 5 of the respondents. The writing task was used to identify the common mistakes that students could make in academic writing. They were asked to write two short paragraphs regarding their fields of work. The questionnaires were used to describe the purpose of the task and gather information from the respondents to get their opinions and ideas about academic writing.

Data Collection: Data collection took place during the second semester of the academic session 2011/2012. In this study, the data was collected from the questionnaires in order to develop the research questions and to collect the intended data.

Data Reliability: For the assessment of data reliability, 40 copies of the instruments were administered to three graduate lecturers at the beginning of the current semester. The other 40 copies were subsequently sent to other persons who are teaching English language from Canada and U.S to ensure the consistency of the questionnaires.

Data Analysis: Data from the questionnaires was analyzed using the latest version of Statistical Package for Social Sciences (SPSS 20.0) to get the findings in order to answer the research questions. For analyzing the questionnaires, the mean and percentages calculated by using SPSS. After the data was collected, the study aimed to identify the data characteristics and results. The questionnaires would have 5 scales to measure the respondents' perceptions, but in the current study a different method was used to analyze the output from the questionnaires. The method dealt with only 4 scales that focused on answering certain questions regarding an agreement or disagreement. The scale used in this study depended on the overall mean consisting of three levels (high, moderate, and low).

For this study, 1 dimensional scaling that was used and respondents were requested to score on the scale of 1-4. This process can identify the problems of academic writing that students faced in their writing by choosing the level of agreement in the given questionnaires. For the writing task, an expert of English language was asked to help and analyze the mistakes the respondents made in the writing task such as organizing paragraphs in relating to punctuation 
marks and conjunctions, paraphrasing, coherence, or expressing students' ideas.

\section{FINDINGS}

\section{Proficiency of Students' English levels}

This section presents the proficiency levels of students based on their own perceptions.

TABLE 1

ENGLISH PROFICIENCY OF STUDENTS

\begin{tabular}{|c|c|c|c|c|c|}
\hline Students & Excellent & Very good & Good & Fair & Poor \\
\hline 1- Iraq & $0(0.0 \%)$ & $9(20.5 \%)$ & $21(50.0 \%)$ & $12(27.3 \%)$ & $1(2.3 \%)$ \\
\hline 2- $\quad$ Yemen & $1(4.3 \%)$ & $6(26.1 \%)$ & $15(65.2 \%)$ & $1(4.3 \%)$ & $0(0.0 \%)$ \\
\hline 3- Syria & $0(0.0 \%)$ & $1(100.0 \%)$ & $0(0.0 \%)$ & $0(0.0 \%)$ & $0(0.0 \%)$ \\
\hline 5- Saudi & $0(0.0 \%)$ & $0(0.0 \%)$ & $1(50.0 \%)$ & $1(50.0 \%)$ & $0(0.0 \%)$ \\
\hline 6- Sudan & $0(0.0 \%)$ & $1(25.0 \%)$ & $3(50.0 \%)$ & $1(25.0 \%)$ & $0(0.0 \%)$ \\
\hline Total & 1 & 21 & 41 & 16 & 1 \\
\hline
\end{tabular}

The table above presents the proficiency levels of students in English academic writing. The majority of Yemeni students $(65.2 \%)$ claimed they had obtained a good level of proficiency regarding their English academic writing skills and $4.3 \%$ of Yemeni students felt that they had an excellent level of proficiency.

By comparison, $50.0 \%$ of Iraqi students expressed that their proficiency level, as presented in the distributed questionnaire was good and 20.5\% felt they had achieved a very good proficiency level. Only $2.3 \%$ rated their skills as poor. Slightly more than half of the students from Sudan (50.5\%), stated that they had a good proficiency level in academic writing, whereas 25.0\% rated their proficiency as fair. (100.0\%) of the Palestinian, Algerian, and Syrian students, on the other hand, felt that they had achieved a very good level of proficiency in English language. Overall, more than 50\% of the respondents assumed that they had a good level of English proficiency.

Findings from research question one (What are the mistakes that Arab students commit in academic writing at UTM?

The two short paragraphs were then analyzed by an expert of English language. The expert highlighted and categorized the students' mistakes according to vocabulary problems, spelling mistakes, expressing ideas, and organizing paragraphs. The findings from the analysis are presented in the table below:

TABLE 2

MisTAKES MADE BY STUDENTS IN THE WRITING TASK

\begin{tabular}{|l|l|l|l|l|l|}
\hline Students & VP & SM & SS & EI & Total \\
\hline S1 & $1(14.2 \%)$ & $1(14.2 \%)$ & $3(42.8 \%)$ & $2(28.5 \%)$ & 7 \\
\hline S2 & $1(12.5 \%)$ & $1(12.5 \%)$ & $5(62.5 \%)$ & $2(25 \%)$ & 8 \\
\hline S3 & - & $7(100 \%)$ & - & 7 \\
\hline S4 & $1(7.6 \%)$ & $7(53.8 \%)$ & $1(7.6 \%)$ & 13 \\
\hline \multicolumn{6}{c|}{ Note: VP= Vocabulary } \\
SS= Sentence Structure \\
EI= Expressing Ideas
\end{tabular}

The table above shows that the most mistakes made by the participants were sentence structure and vocabulary mistakes. For example, the fourth student made the highest number of sentence structure mistakes with 7 sentence structure mistakes (53.8\%), 4 mistakes in vocabulary (30.7\%), and one mistake with both spelling mistakes and expressing ideas (7.6\%). Other students like S1 and S2 also committed many mistakes in academic writing related to spelling (14.2\%) and (12.5\%). The most mistakes they committed also were in sentence structure. The first students committed (42.8\%) and the second students made (62.5\%).

Findings of research question two (What are the problems faced by Arab students in academic writing at UTM)?

The questionnaires included 17 questions and the students were asked to select their level of agreement in order to express their perceptions regarding the causes of their academic writing problems. These questions were found in Section B of the questionnaires. The results for each question of Section B are presented in the following sub-sections. Each sub-sections also presents the percentages and the mean for each construct of academic writing that was examined.

The respondents expressed their opinions towards vocabulary items as being high regarding the average of overall mean. The table below shows the perception of Arab postgraduate students towards the vocabulary as an academic writing problem 
TABLE 3

PERCENTAGE OF STUDENTS' PERCEPTIONS OF VOCABULARY AS AN ACADEMIC WRITING PROBLEM

\begin{tabular}{|c|c|c|c|c|c|c|c|c|}
\hline \multirow{2}{*}{$\begin{array}{l}\text { Questionnaire } \\
\text { Items }\end{array}$} & \multicolumn{8}{|c|}{ Agree (\%) } \\
\hline & $\mathrm{Iq}$ & Yem & $\mathrm{Sa}$ & Sud & Syr & $\mathrm{Al}$ & Lib & Pal \\
\hline Q11 & 59.1 & 56.5 & 100 & 20 & 100 & 100 & 50 & 50 \\
\hline Q12 & 93.2 & 87 & 100 & 100 & 100 & 100 & 100 & 50 \\
\hline Mean & 2.1 & 2.9 & 2.7 & 2.1 & 1.5 & 1.1 & 1.7 & 1 \\
\hline Total Mean & 1.8 & & & & & & & \\
\hline
\end{tabular}

The table above shows that the students from Syria (100\%), Saudi (100\%), and Algerian (100\%) had the highest percentages compared to the other students. So, it can be realized that those students assumed they faced many problems related to vocabulary as presented in the distributed questionnaires.

TABLE 4

PERCENTAGES OF STUDENTS' PERCEPTIONS TOWARDS SENTENCE STRUCTURE AS AN ACADEMIC WRITING PROBLEM

\begin{tabular}{|l|l|l|l|l|l|l|l|l|}
\hline \multirow{2}{*}{ Questionnaires Items } & Agree (\%) & \multicolumn{4}{l|}{ Lib } & Pal \\
\cline { 2 - 11 } & Iq & Yem & Sa & Sud & Syr & Al & Lib \\
\hline Q 18 & 66 & 60.8 & 100 & 80 & 100 & 100 & 50 & 50 \\
\hline Mean & 50 & 60.0 & 100 & 40 & 100 & 100 & 50 & 50 \\
\hline Total Mean & 2.1 & 2.9 & 2.7 & 3.1 & 2 & 1.3 & 1 & 1.2 \\
\hline
\end{tabular}

The table presents the percentages of students' perceptions towards the sentence structure of academic writing. The table shows the overall mean of students' perceptions regarding the sentence structure as an academic writing problem indicating that Iraqi and Sudan students had the same moderate mean of 2.1. So it can be observed that those students face slight challenges related to sentence structure in their academic writing.

Other students, such as those from Yemen, Saudi, Libya, Syria, and Algeria had the highest overall mean ranging from 1.5 to 1.9. These results indicated that those students faced many problems related to sentence structure in their academic writing.

TABLE 5

PERCENTAGES OF STUDENTS' PERCEPTIONS OF GETTING FEEDBACK AND CHALLENGING AS AN ACADEMIC WRITING PROBLEM

\begin{tabular}{|c|c|c|c|c|c|c|c|c|}
\hline \multirow[t]{2}{*}{ Questionnaires items } & \multicolumn{8}{|c|}{ Agree $(\%)$} \\
\hline & $\mathrm{Iq}$ & Yem & $\mathrm{Sa}$ & Sud & Sy & $\mathrm{Al}$ & $\mathrm{Li}$ & Pal \\
\hline Q 6 & 56.8 & 56.5 & 50 & 60 & 0 & 100 & 0 & 50 \\
\hline Q 8 & 81.8 & 82.6 & 100 & 80 & 100 & 100 & 100 & 0 \\
\hline Q 9 & 11.3 & 26.1 & 50 & 0 & 100 & 0 & 0 & 0 \\
\hline Q14 & 31.8 & 47.8 & 50 & 0 & 0 & 0 & 0 & 0 \\
\hline Q16 & 36.3 & 34.7 & 100 & 20 & 0 & 0 & 0 & 0 \\
\hline Q17 & 50 & 26 & 50 & 40 & 100 & 100 & 0 & 0 \\
\hline Mean & 2.9 & 3.0 & 3.2 & 3.3 & 2.5 & 1.8 & 1.3 & 2 \\
\hline Total Mean & 2.5 & & & & & & & \\
\hline
\end{tabular}

The table shows the percentages of students' perceptions related to getting feedback or practicing as an academic writing problem. For instance, Syrian (100\%), Saudi (100\%), and Algeria (100\%) had the highest percentage towards this item. It means that those students faced many problems in academic writing related to getting feedback and other items.

Other students from Iraq, Yemeni, and Sudan had different perceptions related to receiving feedback and skill practice. The overall mean for these students ranged from moderate (2.9) to low (3.3). These students claimed that they faced only slight challenges related to receiving feedback or practicing their academic writing skills.

\section{CONCLUSION}

This study was conducted to investigate the types of mistakes and problems with academic writing experienced by Arab speaking students at UTM. Also, this chapter proposes recommendations for further research. A total of 80 respondents completed the questionnaires based on their perceptions towards the causes of academic writing problems. Another 5 students were asked to write two short paragraphs regarding a simple writing task. The study was conducted during the second semester of 2011/2012.

The findings of the study also showed that students committed many mistakes in academic writing in relation to sentence structure, vocabulary, and expressing ideas. The results presented the most mistakes made by the participants in a simple writing task. The mistakes were ranged from the highest percentages to the lowest in relation to the aspects of academic writing problems. The fourth student made the highest number of sentence structure mistakes with 7 sentence structure errors (53.8\%), 4 mistakes in vocabulary (30.7\%), and one mistake with both spelling and expressing ideas $(7.6 \%)$. Other students like S1 and S2 also committed many mistakes in academic writing related to spelling with $(14.2 \%)$ and $(12.5 \%)$ respectively. Most mistakes committed also were in sentence structure. The first student 
committed $(42.8 \%)$ and the second student made $(62.5 \%)$. The findings also shows information highlighted in the questionnaires like demographic information of the respondents and the causes of academic writing problems. This section also discusses the levels of overall mean among the students that have already been presented and highlighted.

\section{Recommendations for future research}

Many factors can be observed regarding the results of the questionnaires and writing task. These factors should be taught with precision at schools, universities, and English training institutions. The students need to see the whole picture of the methods used in academic writing that involve using certain strategies and steps to improve their writing skills.

English language specialists and lecturers used strategies to teach academic writing like constructivist approach. It can provide learners with the chance to gain experience practicing academic writing and to focus on the aspects of teaching academic writing such as daily writing practice, and to reveal their abilities and skills in terms of direct interaction with native speakers in using the appropriate sentence structures. So, learners may enhance their attitudes and perceptions when communicating with native speakers of English language. In other words, brainstorming and mind-mapping can be used among students to enhance their ideas and writing styles in discussing and group working.

There are some other factors that can be developed for future research to help students produce a good piece of academic writing. One of these factors is increasing students' motivation towards writing by using different styles of sentence structures, good vocabulary, and organizing their ideas and critical thinking. Actually, this could happen if the division and persons in charge of teaching academic writing had obtained effective and adequate methods that other researchers and scholars use in delivering information about academic writing. Moreover, Arab students can motivate themselves to learn English, as a genuine interest in the target language can inspire students to improve their abilities to express themselves in English.

Other studies should be undertaken to understand and explore the causes behind the problems of academic writing. It may be because of the English curriculum, the lack of Arab educational systems, and snowballing techniques that are used in the distributed questionnaires. To have a better inference for this kind of study, it may be suggested that a more systematic sample procedure be taken.

\section{REFERENCES}

[1] Abdulwahed, S. (2010). Exploring Students' Perceptions of ESL Writing. English Language Teaching. Vol 4, 73-80.

[2] Daoud, S., \& Al-Hazmi, S. (2002, 4-16 March). Teaching Writing through Reflection and Thinking. Paper presented at the TESOL Arabia Conference, Abu Dhabi.

[3] Ferris, D. R., \& Hedgcock, J. S. (2005). Teaching ESL composition: Purpose, process and practice. Mahwah, NJ: Lawrence Erlbaum Associates.

[4] Ellis, R. (1985). Understanding second language acquisition. Oxford: Oxford University Press.

[5] Fawwaz, A.-H., \& Ahmed, A. (2007). Discourse problems in argumentative writing. Language \& Linguistics, 13(3).

[6] Kepner, C. G. (1991). An experiment in the relationship of types of written feedback to the development of second-language writing skills. Modern Language Journal, 75(3), 305-313.

[7] Lundstrom, K., \& Baker, W. (2009). To give is better than to receive. Journal of Second Language Writing, 18(1), 30-43.

[8] Li, X. (2007). Identities and beliefs in ESL writing: From product to processes. TESL Canada Journal, 25(1), 41-64.

[9] Montgomery, J., \& Baker, W. (2007). Teacher-written feedback: Student perceptions, teacher self-assessment, and actual teacher performance. Journal of Second Language Writing, 16(2), 82-99.

[10] Rabab'ah, G. (2001). Communication Problems Facing Arab Learners of English. Journal of Language \& Learning, 3(1), 180197.

[11] Zamel, V. (1983). The composing processes of advanced ESL students: six case studies.

Mustafa N Abdulkareem is currently a PhD candidate, studying in the Department of curriculum and Instruction, Universiti Teknologi Malaysia, Johor, Malaysia.

Mustafa received his BSc degree in Iraq-Basra-University of Basra in linguistics fields/ College of Education-Dept of English Language 2004 and MSc in Universiti Teknologi Malaysia, Johor, Malaysia / academic writing/ College of Education 2012. Also, his current research interest is in academic writing, translation, and using idiomatic expressions in phrases. 